\title{
Article \\ Optimization of Bioactive Polyphenols Extraction from Picea Mariana Bark
}

\author{
Nellie Francezon 1,2, Naamwin-So-Bâwfu Romaric Meda ${ }^{1,2}$ and Tatjana Stevanovic 1,2,* \\ 1 Renewable Materials Research Centre, Department of Wood and Forest Sciences, Université Laval, Québec, \\ QC G1V 0A6, Canada; nellie.francezon.1@ulaval.ca (N.F.); romaric.meda.1@ulaval.ca (N.-S.-B.R.M.) \\ 2 Institute of Nutrition and Functional Food (INAF), Université Laval, Quebec, QC G1V 0A6, Canada \\ * Correspondence: tatjana.stevanovic@sbf.ulaval.ca; Tel.: +1-418-656-2131
}

Received: 30 October 2017; Accepted: 30 November 2017; Published: 1 December 2017

\begin{abstract}
Reported for its antioxidant, anti-inflammatory and non-toxicity properties, the hot water extract of Picea mariana bark was demonstrated to contain highly valuable bioactive polyphenols. In order to improve the recovery of these molecules, an optimization of the extraction was performed using water. Several extraction parameters were tested and extracts obtained analyzed both in terms of relative amounts of different phytochemical families and of individual molecules concentrations. As a result, low temperature $\left(80^{\circ} \mathrm{C}\right)$ and low ratio of bark/water $(50 \mathrm{mg} / \mathrm{mL})$ were determined to be the best parameters for an efficient polyphenol extraction and that especially for low molecular mass polyphenols. These were identified as stilbene monomers and derivatives, mainly stilbene glucoside isorhapontin (up to $12.0 \%$ of the dry extract), astringin (up to $4.6 \%$ ), resveratrol (up to $0.3 \%$ ), isorhapontigenin (up to $3.7 \%$ ) and resveratrol glucoside piceid (up to $3.1 \%$ ) which is here reported for the first time for Picea mariana. New stilbene derivatives, piceasides $\mathrm{O}$ and $\mathrm{P}$ were also characterized herein as new isorhapontin dimers. This study provides novel information about the optimal extraction of polyphenols from black spruce bark, especially for highly bioactive stilbenes including the trans-resveratrol.
\end{abstract}

Keywords: Picea mariana; bark; hot water extraction; chemometrics; stilbenes; piceaside

\section{Introduction}

Black spruce (Picea mariana (Mill.) Britton, Sterns \& Poggenb.) is an economically highly appreciated species of the Canadian boreal forest especially for the quality of its wood. Consequently, black spruce bark, a by-product of wood transformation, is available in large quantities. Produced at around 920,000 dry metric tons per year in Québec, spruce bark is mostly burnt to produce energy. However, this biomass rich in bioactive molecules could benefit from new alternative solution for its management. Recently identified in black spruce bark extract [1], trans-resveratrol, which had been studied for its multiple therapeutic properties, was found in our recent study [2] in greater concentration in black spruce bark extract (up to $667 \mathrm{mg} / 100 \mathrm{~g}$ of dry extract) than in common food sources such as red wine, grape skin or cocoa $[3,4]$. Several other active compounds identified in black spruce bark extracts such as taxifolin, pinoresinol, isolariciresinol, mearnsetin, are known for their strong antioxidant and anti-inflammatory properties [1]. Stilbenes phytoalexines isorhapontin, astringin, isorhapontigenin and piceatannol [5] were reported to be associated with antimicrobial properties, but also for therapeutic potential as antioxidant, cardioprotective, anti-inflammatory and anticancer [6,7]. Easily recoverable through simple water extraction, trans-resveratrol and others bioactive polyphenols could become available from black spruce bark feedstock as potential active ingredients for cosmetics, functional foods or pharmaceuticals. Moreover, acute oral toxicity of black spruce bark hot water extract obtained from our laboratory was tested on Sprague-Dawley rats on 
preliminary in vivo trials. With an average median lethal concentration $\mathrm{LD}_{50}$ toxicity greater than $2000 \mathrm{mg} / \mathrm{kg}$, this study concluded that black spruce hot water extract showed no toxicity [8].

With the growing interest for eco-friendly chemical procedures and very strict food and cosmetics industry regulations, green processes have become of growing interest for natural ingredient extractions [9]. Among green solvents, water is of particular interest as non-toxic, non-flammable, cheap and easily available. Even if water is not the best solvent to extract active polyphenolic molecules, it still possesses remarkably flexible physico-chemical properties that can be exploited to increase the extraction selectivity [10].

Black spruce bark hot water extract has been studied as a new source of bioactive compounds, but no research has been performed so far to improve their quantity. Taking into account that purification methods are time-consuming and laborious, using rather a more selective extraction represents an interesting approach. Therefore, this study aimed to optimize the hot water extraction of bark, using factorial experimental design and high-performance liquid chromatography (HPLC) fingerprint analysis. To the best of our knowledge, this is the first study that explores the potential of chemometric based approach to determine the effects of extraction parameters on individual quantity of selected compounds from black spruce bark extract. The identification and quantification of molecules present in black spruce bark hot water extract helped us evaluate this extract as a potential health product.

\section{Results and Discussion}

\subsection{Effects of Extraction Parameters on Multiple Response Factors}

Multiple response factors (Table 1) were evaluated in this factorial design in order to understand how they were affected by extraction parameters. Factorial analysis of variance (ANOVA) was performed on the yield, the total phenolic content, total sugar content, total proanthocyanidin content and antioxidant activity of the 18 different extracts in duplicates. As for significant results, contrasts analysis was conducted in order to determine the main influencing parameter.

Table 1. Factorial design for the optimization of black spruce bark extraction.

\begin{tabular}{|c|c|c|c|c|c|c|c|c|}
\hline \multicolumn{4}{|c|}{ Experimental Design } & \multicolumn{5}{|c|}{ Response Factors } \\
\hline $\begin{array}{l}\text { Extract } \\
\text { Name }\end{array}$ & $\begin{array}{l}\text { Time } \\
\text { (min) }\end{array}$ & $\begin{array}{c}\text { Temperature } \\
\left({ }^{\circ} \mathrm{C}\right)\end{array}$ & $\begin{array}{c}\text { Ratio } \\
(\mathrm{mg} / \mathrm{mL})\end{array}$ & Yield (\%) & $\begin{array}{c}\text { Phen } \\
\text { (mg GAE/g) }\end{array}$ & $\begin{array}{c}\text { PA } \\
(\mathrm{mg} \mathrm{CyE} / \mathrm{g})\end{array}$ & $\begin{array}{c}\text { Sugar } \\
\text { (mg ARGF/g) }\end{array}$ & $\begin{array}{c}\text { Antiox } \\
(\mu \mathrm{mol} \mathrm{TE} / \mathrm{g})\end{array}$ \\
\hline $\mathrm{A}$ & 60 & 80 & 200 & $11.3 \pm 0.4$ & $442 \pm 25$ & $224 \pm 8$ & $662 \pm 77$ & $1021 \pm 54$ \\
\hline B & 60 & 100 & 200 & $14.3 \pm 0.7$ & $471 \pm 6$ & $252 \pm 2$ & $581 \pm 3$ & $1082 \pm 29$ \\
\hline $\mathrm{C}$ & 60 & 80 & 100 & $14.5 \pm 0.4$ & $469 \pm 5$ & $236 \pm 15$ & $543 \pm 49$ & $1087 \pm 19$ \\
\hline $\mathrm{D}$ & 60 & 100 & 100 & $17.7 \pm 0.3$ & $472 \pm 27$ & $254 \pm 8$ & $574 \pm 7$ & $1071 \pm 14$ \\
\hline E & 60 & 80 & 50 & $15.6 \pm 0.5$ & $485 \pm 4$ & $252 \pm 16$ & $604 \pm 24$ & $1007 \pm 101$ \\
\hline F & 60 & 100 & 50 & $19.3 \pm 0.2$ & $468 \pm 2$ & $264 \pm 1$ & $556 \pm 21$ & $1091 \pm 6$ \\
\hline G & 90 & 80 & 200 & $11.5 \pm 0.5$ & $456 \pm 5$ & $245 \pm 1$ & $608 \pm 71$ & $1029 \pm 52$ \\
\hline $\mathrm{H}$ & 90 & 100 & 200 & $14.6 \pm 0.2$ & $426 \pm 15$ & $232 \pm 20$ & $600 \pm 13$ & $1017 \pm 64$ \\
\hline I & 90 & 80 & 100 & $14.5 \pm 0.3$ & $486 \pm 19$ & $249 \pm 14$ & $606 \pm 9$ & $1079 \pm 9$ \\
\hline $\mathrm{J}$ & 90 & 100 & 100 & $18.1 \pm 0.4$ & $438 \pm 3$ & $232 \pm 1$ & $555 \pm 25$ & $1047 \pm 30$ \\
\hline $\mathrm{K}$ & 90 & 80 & 50 & $16.1 \pm 0.2$ & $472 \pm 3$ & $246 \pm 34$ & $538 \pm 24$ & $1061 \pm 11$ \\
\hline L & 90 & 100 & 50 & $19.4 \pm 0.6$ & $459 \pm 10$ & $243 \pm 3$ & $573 \pm 37$ & $991 \pm 56$ \\
\hline M & 120 & 80 & 200 & $11.2 \pm 0.2$ & $464 \pm 45$ & $245 \pm 3$ & $571 \pm 23$ & $901 \pm 174$ \\
\hline $\mathrm{N}$ & 120 & 100 & 200 & $14.7 \pm 0.3$ & $399 \pm 9$ & $220 \pm 15$ & $637 \pm 4$ & $1026 \pm 62$ \\
\hline $\mathrm{O}$ & 120 & 80 & 100 & $15.1 \pm 0.4$ & $467 \pm 35$ & $235 \pm 15$ & $617 \pm 21$ & $962 \pm 87$ \\
\hline $\mathrm{P}$ & 120 & 100 & 100 & $18.8 \pm 0.4$ & $447 \pm 1$ & $238 \pm 4$ & $673 \pm 6$ & $1049 \pm 27$ \\
\hline Q & 120 & 80 & 50 & $16.5 \pm 0.1$ & $445 \pm 5$ & $244 \pm 6$ & $579 \pm 7$ & $1086 \pm 17$ \\
\hline $\mathrm{R}$ & 120 & 100 & 50 & $20.1 \pm 0.7$ & $502 \pm 56$ & $236 \pm 17$ & $534 \pm 11$ & $1075 \pm 20$ \\
\hline
\end{tabular}

Response factor results are expressed as means and standard deviations from extracts in duplicates. Statistical analysis (factorial analysis of variance (ANOVA) and contrasts) are available in Table S1 Supplementary Material. Phen: total phenol content; PA: Proanthocyanidin content; Antiox: Antioxidant capacity; GAE: Gallic Acid Equivalent; CyE: Cyanidin Equivalent; ARGF: Arabinose-Rhamnose-Galactose-Fructose equivalent; TE: Trolox Equivalent; Results are expressed on $g$ of dry extract.

\subsubsection{Extractable Matter Yields}

Highly significant in the ANOVA analysis, the extraction yield is the most affected response factors. Indeed, its value may double (from $11.2 \pm 0.2 \%$ to $20.1 \pm 0.7 \%$ ) depending on the extraction 
parameters applied. The yield is one of the most important factor studied during optimization of the extraction because it determines the effectiveness of a process. In order to understand which parameters are influencing, further statistical analysis, simple contrasts, were performed (Table S1 Supplementary Material). The temperature and the ratio (bark/solvent) were demonstrated to highly affect the yield with a $p$-value below $5 \%$. As previously reported in literature for yet another bark extraction [11], the yield is inversely proportional to the ratio (Table 1). The less the bark the larger contact area between the solvent and the raw material which decreases consequently saturation of water with extracted compounds. As for extraction temperature, applying $100{ }^{\circ} \mathrm{C}$ instead of $80^{\circ} \mathrm{C}$ globally resulted in $3 \%$ increase of yields. Thus, ratio $50 \mathrm{mg} / \mathrm{mL}$ and $100{ }^{\circ} \mathrm{C}$ temperature have been considered and adopted as the best parameters for an optimized yield.

\subsubsection{Phenolic, Proanthocyanidin Contents and Antioxidant Capacity}

As reported in multiple studies, softwood barks are very rich source of phenolic compounds, known for their health benefits $[12,13]$. An estimation of the total phenolic content was measured with the Folin-Ciocalteu colorimetric test, a fast and easy method, notably adapted to screening between extracts. Results demonstrated quite high polyphenol rate in black spruce bark extract, varying between $399 \pm 9 \mathrm{mg}$ gallic acid equivalent (GAE)/g to $502 \pm 56 \mathrm{mg} \mathrm{GAE} / \mathrm{g}$, in accordance with previously reported studies on black spruce bark $[12,14]$. These results had significant differences at $p<5 \%$ according to ANOVA, and simple contrasts revealed that the ratio was the influencing parameter (Table S1 Supplementary Material). The lower the ratio, the higher the total phenol content (Table 1). Thus, the extraction of phenolic compounds is enhanced by the decrease of ratio. However, among phenolic compounds, the water-soluble condensed tannins (proanthocyanidins) seemed to be unaffected by extraction optimization. Results obtained for the screening of the 36 extracts on proanthocyanidin content using acidic butanol assay were relatively constant around $242 \pm 6 \% \mathrm{mg}$ cyanidin equivalent (CyE)/g of dry extract (Table 1). Indeed, no significant differences between the 18 extraction parameter combinations was reported on the ANOVA (Table S1 Supplementary Material). Thus, as polymeric phenolic compounds showed stable quantities, it seemed highly relevant to further study the variation of low molecular mass phenolic compounds in black spruce bark factorial design extraction.

Previous studies on black spruce bark hot water extract have demonstrated its important antioxidant activity [14]. Free radical scavenging activity using 2,2-diphenyl-1-picrylhydrazyl (DPPH) was screened on the 36 different extracts but no significant difference was determined according to ANOVA (Table S1 Supplementary Material). With very high values from $901 \pm 174$ to $1091 \pm 6 \mu \mathrm{mol}$ trolox equivalent (TE)/g dry extract, not only antioxidant activity equaled commercially available Oligopin's (1056 $\pm 79 \mu \mathrm{mol} \mathrm{TE} / \mathrm{g}$ dry extract) [2] but it has also been preserved regardless of the extraction parameters applied.

\subsubsection{Other Phytochemicals}

The composition of the hot water extract of black spruce bark in terms of nitrogen and sugars contents were also investigated. Nitrogen contents in black spruce bark, which could be either from proteins or alkaloids [15], was found to be very low, around $0.24 \pm 0.04 \%$ of total dry extract (data not shown). Thus, no further analysis was performed. On the other hand, soluble sugars are important constituents of spruce bark, either as free sugars or part of glycosides when linked to molecules such as polyphenols. Thus, stilbene glycosides content was reported to reach $10 \%$ of spruce bark Picea abies dry extract, accounting therefore for an important amount of total sugars [16]. Carbohydrates from spruce bark were reported to be mainly represented by glucose, mannose, galacturonic acid, glucuronic acid and galactose [16]. Approximate analysis of sugar content in natural extracts can be determined using the phenol-sulfuric acid method, which takes into account non-cellulosic bonded and free saccharides. In black spruce bark extracts, sugar content was determined from $534 \pm 11$ to $673 \pm 6 \mathrm{mg}$ arabinose-rhamnose-galactose-fructose equivalent (ARGF)/g dry extract (Table 1), which 
represents important amount. As ANOVA confirmed significant differences between the extracts, simple contrasts were conducted and revealed that ratio was once again the most influential extraction parameter (Table S1 Supplementary Material). As a matter of facts, higher ratio $(200 \mathrm{mg} / \mathrm{mL})$ appeared to be more favorable to sugar extraction (Table 1), as previously reported [17]. Interestingly, the higher the sugar content, the lower the total phenol content. This observation could be related to the greater affinity of sugar with hot water than that of less polar polyphenols [18]. Thus, a high ratio resulted in quick water saturation with carbohydrates, leaving behind the extraction of polyphenols.

\subsection{High Performance Liquid Chromatography Fingerprint and Chemometric Analysis of Black Spruce Bark} Extract Low Molecular Weight Phenolic Compounds

Fingerprint analysis with HPLC-Diode array detection (DAD) has been the method of choice for quality test or to determine the origin of herbal drugs and products [19]. In those applications, low molecular weight phenolic compounds were considered efficient descriptors of some of the product's features, often based on polyphenolic characteristic chemical profiles [20]. Stilbene compounds can be considered chemotaxonomic features of Picea species. Taking into account that their maxima of absorption is around $320 \mathrm{~nm}$, this wavelength was chosen for further analysis of chromatographic profiles by chemometric analysis.

HPLC phenolic profiles of the 36 extracts are quite similar with slight quantitative differences (Figure 1). The targeted 8 main peaks exhibit essentially the same pattern in terms of concentration proportions. Hence, a chemometric analysis was performed using Principal Component Analysis (PCA) to highlight the variability of phenolic composition as a function of the extraction parameters used. PCA is a powerful tool and probably the most frequently used chemometric technique for analyzing complex multivariate measurements in chemistry. In PCA, the most important information of the dataset is condensed into synthetic linear combinations of the variables called Principal Components (PC). Their graphical representations, the component pattern and the scores plot, contribute to a better understanding and visualization of the multidimensional dataset they summarized [20].

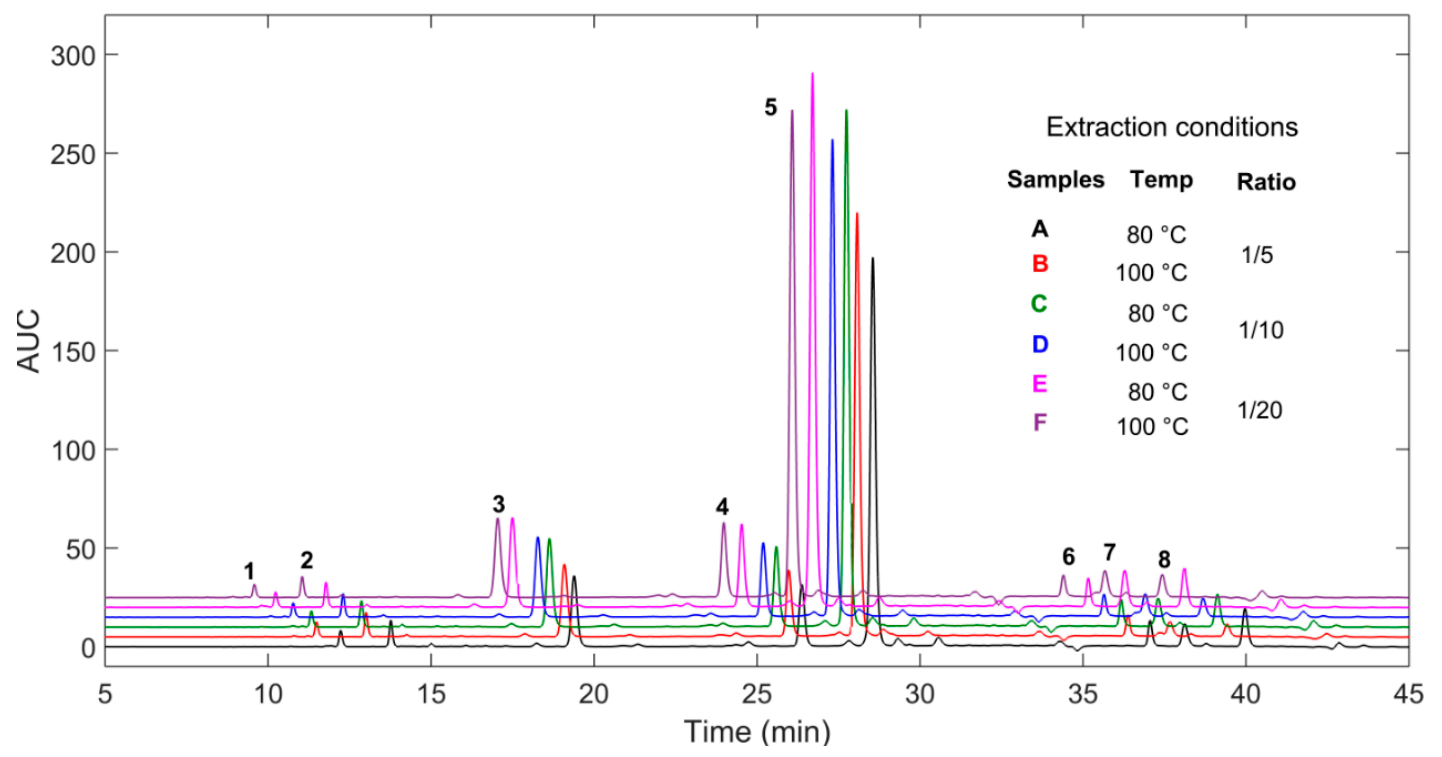

Figure 1. Superposed chromatogram profiles of some of the 36 extracts.

The explorative analysis of the eight main monomeric compounds relative amounts in the 36 extracts revealed that the first three principal components PC1 (49.9\%), PC2 (28.5\%) and PC3 $(8.2 \%)$ explained $86.7 \%$ of the total variance, which is highly representative of the model (Figure S1 Supplementary Material). Correlation analysis (Table S2 Supplementary Material) revealed that compounds 1 and 2 were highly correlated with PC2 (respective correlation coefficient of 0.96 and 
0.93) and compounds 4, 5, 7 and 8 with PC1 (respective correlation coefficient $0.86,0.89,0.87,0.81$ ). The correlation circle (Figure 2A) which illustrate the variables according to the PCs, confirmed the high correlation of the compounds to both of the PCs. Compounds $\mathbf{3}$ and $\mathbf{6}$ were less explicative of the model as they were not well projected on the PCs. None of the compounds was correlated with PC3, thereby, only PC1 and PC2 (which represents 78.4\% of the total variance) were retained for the analysis. The score plot (Figure 2B) which represents the distribution of the extracts according to the PC1 and PC2, revealed a division tendency of two groups as a function of temperature. Extracts produced at $80{ }^{\circ} \mathrm{C}$ seemed to gather in the upper right part (with positive coordinates for PC1 and PC2) and $100{ }^{\circ} \mathrm{C}$ extracts in the lower left part (with negative coordinates).

A

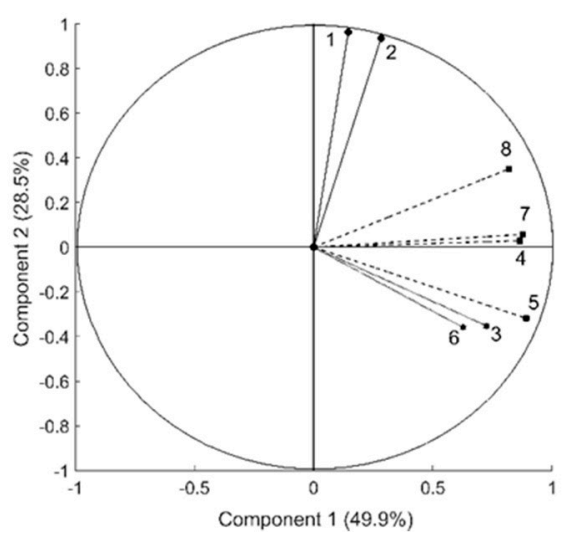

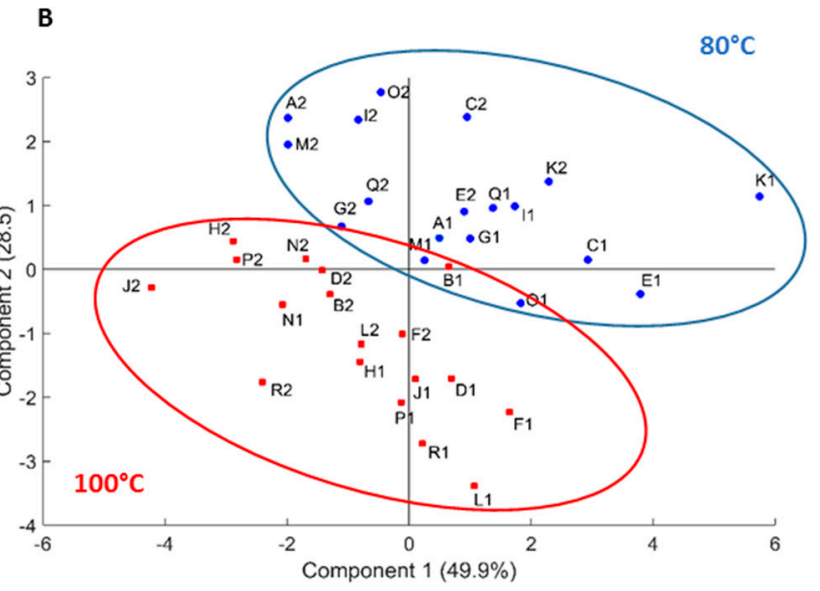

Figure 2. Principal component analysis of the 36 extracts of black spruce bark; (A) Correlation circle which displays the 8 targeted molecules correlations on the two principal components (axes); (B) Score plot of the 36 extracts (A1 to R2) in function of the two principal components.

Moreover, the sum of variables 1 and 2 is even more correlated to PC 2 that the components taken individually. As a matter of fact, compounds 1 and 2 can be gathered into a group of molecules, group A. This also applies to compounds 4, 5, 7 and 8 with PC1, therefore they will be considered as another group, group B. The $80^{\circ} \mathrm{C}$ extracts are mostly congregated according to group A and B direction. Considering the values of the projections of the $80^{\circ} \mathrm{C}$ extracts on $\mathrm{PC} 1$, they all demonstrated positive coordinates which means that the $80{ }^{\circ} \mathrm{C}$ extracts concentrated higher quantities of $\mathrm{A}$ and $\mathrm{B}$ groups than the extracts obtained at $100^{\circ} \mathrm{C}$.

Despite the fact that none of the extraction parameters seemed suitable to preferentially extract selected compounds from the others, PCAs, representing $76.4 \%$ of the model, allowed to highlight two groups of compounds which seemed to have the same tendencies and which were both influenced by the extraction temperature. In order to support this conclusion, the 8 compounds needed to be identified.

\subsection{Isolation, Identification and Quantification of Low Molecular Weight Phenolic Constituents of Black Spruce Bark Extract}

The eight targeted phenolic compounds were therefore purified using silica and sephadex open columns and semi-preparative chromatography. Their characterization was achieved using a combination of ultraviolet (UV) profiles, mass spectra and nuclear magnetic resonance (NMR) shifts (Table 2). Compounds of group A were found to be glycosylated hydroxycinnamic acids, namely trans- $p$-coumaric acid $\beta$-D-glucopyranoside (1) and trans-ferulic acid $\beta$-D-glucopyranoside (2) (Figure 3). Their glucose moiety was confirmed to be linked to carbon 4 (position para) by nuclear overhauser spectroscopy (NOESY) analysis. The trans-p-coumaric acid, the trans-ferulic acid and their glycosides were previously reported in Picea mariana and other Picea species [1,21]. 
However, this is the first time that glucose-bound coumaric and ferulic acids (1) and (2) are reported in Picea mariana. Interestingly, several studies referred to these hydroxycinnamic acids as widely distributed among gymnosperms as bound to cell-wall [22]. As for the group B compounds, they are all stilbene derivatives. Molecules 4 and 5 were determined to be stilbene glycosides trans-piceid (4) and trans-isorhapontin (5) (Figure 3). To the best of our knowledge, this is the first time that trans-piceid was reported in P. mariana. Their aglycons are identified as trans-resveratrol (7) and trans-isorhapontigenin (8) (Figure 3). Even if not included in group B, compound 3 is a member of the stilbene family, identified as trans-astringin, a piceatannol glucoside (Figure 3).<smiles>[R]c1ccc(C=CC(=O)O)cc1[R]</smiles>

(1) $R_{1}=O G l u ; R_{2}=H$

(2) $R_{1}=$ OGlu; $R_{2}=O \mathrm{OCH}_{3}$

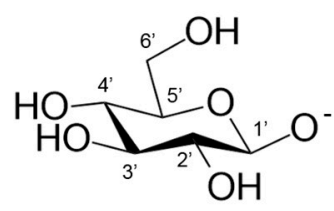

OGlu : Glucose moiety<smiles>[R]c1cc(O)cc(/C=C/c2ccc(O)c([R2])c2)c1</smiles>

(3) $\mathrm{R}_{1}=\mathrm{OGlu} ; \mathrm{R}_{2}=\mathrm{OH}$

(4) $R_{1}=$ OGlu; $R_{2}=H$

(5) $R_{1}=$ OGlu; $R_{2}=O \mathrm{OCH}_{3}$

(7) $\mathrm{R}_{1}=\mathrm{OH} ; \mathrm{R}_{2}=\mathrm{H}$

(8) $\mathrm{R}_{1}=\mathrm{OH} ; \mathrm{R}_{2}=\mathrm{OCH}_{3}$

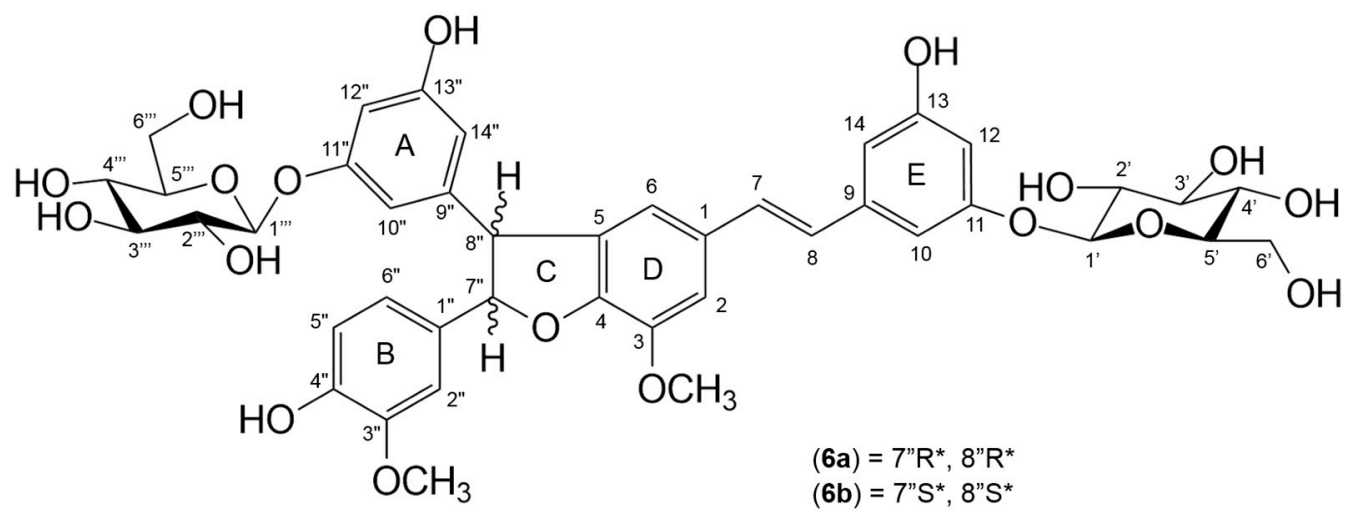

Figure 3. Structures of the molecules isolated from black spruce hot water extract. 
Table 2. Identification and quantification data for the 8 phenolic compounds isolated from black spruce bark extract.

\begin{tabular}{|c|c|c|c|c|c|c|c|c|c|c|c|}
\hline \multirow[b]{2}{*}{ Comp. } & \multirow[b]{2}{*}{ Ret. Time (min) } & \multicolumn{4}{|c|}{ Identification } & \multicolumn{6}{|c|}{ Quantification } \\
\hline & & $\lambda_{\max }(\mathrm{nm})$ & Exact Mass & Formula & Suggested Compound & Regression Equation & $R^{2}$ & Linear Range ug/mL & LOD & LOQ & $\begin{array}{l}\text { Concentration Range } \\
\mathrm{mg} / 100 \mathrm{~g} \text { Dry Extracts }\end{array}$ \\
\hline 1 & 12.4 & 290 & 326.0994 & $\mathrm{C}_{15} \mathrm{H}_{18} \mathrm{O}_{8}$ & trans-p-coumaric acid $\beta$-D-glucopyranoside & $y=2140.2 x+8.2609$ & 0.9997 & $5-500$ & 0.1 & 0.4 & $160-265$ \\
\hline 2 & 13.9 & 290,315 & 356.1093 & $\mathrm{C}_{16} \mathrm{H}_{20} \mathrm{O}_{9}$ & trans-ferulic acid $\beta$-D-glucopyranoside & $y=1486.4 x-60.765$ & 0.9987 & 5-1000 & 0.4 & 1.3 & 894-1073 \\
\hline 3 & 20.2 & 325,305 & 406.1243 & $\mathrm{C}_{20} \mathrm{H}_{21} \mathrm{O}_{9}$ & trans-astringin & $y=2284 x-441.91$ & 0.999 & 5-1000 & 3.8 & 11.4 & $2272-4613$ \\
\hline 4 & 26.8 & 305,320 & 390.1303 & $\mathrm{C}_{20} \mathrm{H}_{22} \mathrm{O}_{8}$ & trans-piceid & $y=3384.1 x-528.13$ & 0.9971 & $5-500$ & 0.2 & 0.6 & 1805-3094 \\
\hline 5 & 29.4 & $325,303,290$ & 420.1416 & $\mathrm{C}_{21} \mathrm{H}_{24} \mathrm{O}_{9}$ & trans-isorhapontin & $y=2944.6 x-265.82$ & 0.9979 & $1-1000$ & 0.6 & 1.9 & $4256-11971$ \\
\hline 6 & 37.3 & $330,310,283$ & 838.2684 & $\mathrm{C}_{42} \mathrm{H}_{46} \mathrm{O}_{18}$ & piceaside $\mathrm{O}$ and $\mathrm{P}$ & $y=1056.4 x-329.29$ & 0.9933 & $1-1000$ & 0.4 & 1.2 & $3508-4853$ \\
\hline 7 & 38.5 & 305,320 & 228.0796 & $\mathrm{C}_{14} \mathrm{H}_{12} \mathrm{O}_{3}$ & trans-resveratrol & $y=7520.7 x+43.49$ & 0.9914 & $1-500$ & 0.2 & 0.6 & $53-302$ \\
\hline 8 & 40.3 & $325,303,290$ & 258.0892 & $\mathrm{C}_{15} \mathrm{H}_{14} \mathrm{O}_{4}$ & trans-isorhapontigenin & $y=2062.4 x-415.08$ & 0.9979 & 5-1000 & 0.3 & 0.9 & $2257-3654$ \\
\hline
\end{tabular}

Comp.: compound number; Ret. time: retention time; $\lambda_{\max }$ : maximal wavelength value; Exact mass calculated from $m / z$ (mass-to-charge ratio); $R^{2}$ : coefficient of determination; LOD: Limit of detection, LOQ: Limit of quantification. 
As for the compound 6, no match for its molar mass was found in the literature, hence further analysis were performed. Positive high resolution mass spectrometry showed a unique $\left[\mathrm{M}+\mathrm{NH}_{4}\right]^{+}$ ion peak at $m / z=856.3026$ (originally calculated exact mass $=838.2684$ ) from which was generated the molecular formula $\mathrm{C}_{42} \mathrm{H}_{46} \mathrm{O}_{18}$. High molar mass molecules from Picea abies had been previously reported in the literature as stilbene dimers, named piceasides $[23,24]$. To date, fourteen piceasides (A to N) had been identified, but none of them corresponded to a molecular mass of 838. Therefore, structural elucidation of 6 was performed using $1 \mathrm{D}\left({ }^{1} \mathrm{H},{ }^{13} \mathrm{C}\right)$ and $2 \mathrm{D}$ NMR analyses. Interestingly, the ${ }^{13} \mathrm{C}$ NMR spectrum displayed signals in doublet (Table 3), which is characteristic of a mix of stereoisomers such as diastereoisomers. Moreover, ${ }^{1} \mathrm{H}$ NMR spectrum showed two sets of signals overlapped or partially overlapped, confirming the diastereoisomers hypothesis as previously demonstrated for Picea abies stilbene dimers by Li et al. [23]. A careful assignment of NMR shifts signals for both $\mathbf{6 a}$ and $\mathbf{6 b}$ is presented in details in Table 3 and confirmed with literature [23,24]. The aromatic area of the spectrum was composed of two overlapped olefinic protons [6a and $6 \mathbf{b}: \delta_{\mathrm{H}} 7.03(\mathrm{H7})$, $6.87(\mathrm{H} 8)]$ with $16 \mathrm{~Hz}$ characteristic coupling constants of a trans-substituted double bond and four aromatic rings : two totally overlapping $\mathrm{ABC}$ spin system of each $\mathbf{6 a}$ and $\mathbf{6 b}$ 1,3,4-trisubstituted phenyl rings (ring B) $\left[\delta_{\mathrm{H}} 6.93\left(\mathrm{H} 2^{\prime \prime}\right), 6.80\left(\mathrm{H}^{\prime \prime}\right), 6.79\left(\mathrm{H} 5^{\prime \prime}\right)\right]$, two partially overlapping $\mathrm{ABC}$ spin system of 1,3,5-trisubstituted phenyl rings (ring A) [6a: $\delta_{\mathrm{H}} 6.42$ (H10"), 6.50 (H12"), 6.34 (H14"), 6b: $\left.\delta_{\mathrm{H}} 6.42\left(\mathrm{H} 10^{\prime \prime}\right), 6.50\left(\mathrm{H} 12^{\prime \prime}\right), 6.31\left(\mathrm{H} 14^{\prime \prime}\right)\right]$, two overlapping ABC spin system of each $\mathbf{6 a}$ and $\mathbf{6 b}$ 1,3,5-trisubstituted phenyl rings (ring E) [ $\delta_{\mathrm{H}} 6.78$ (H10), 6.45 (H12), 6.62 (H14)] and two overlapping AM system of $\mathbf{6 a}$ and $\mathbf{6 b}$ 1,3,4,5-tetrasubstituted phenyl rings (ring D) [ $\delta_{\mathrm{H}} 7.11(\mathrm{H} 2), 6.83(\mathrm{H} 6)$ ] (Figure 3). Spectrum area between $\delta_{\mathrm{H}} 5.5$ and 4.4 displayed partially overlapping AX spin system of two dehydrobenzofuran moieties (ring C) [6a: $\delta_{\mathrm{H}} 5.43$ (H7"), $4.51\left(\mathrm{H} 8^{\prime \prime}\right), 6 \mathbf{b}: \delta_{\mathrm{H}} 5.44\left(\mathrm{H} 7^{\prime \prime}\right), 4.50$ $\left(\mathrm{H} 8{ }^{\prime \prime}\right)$ ] and protons at anomeric carbons of glucose moieties [6a: $\delta_{\mathrm{H}} 4.87$ (H1'), 4.79 (H1''), 6b: 4.87 $\left.\left(\mathrm{H} 1^{\prime}\right), 4.90\left(\mathrm{H} 1^{\prime \prime \prime}\right)\right]$. Finally, the area between $\delta_{\mathrm{H}} 3.93-3.31$ with overall overlapping signals indicated the presence of four glucose moieties, two for each diastereoisomers, and two overlapping signals integrating for $6 \mathrm{H}$ each, characteristic of methoxyl groups. [6a: $\delta_{\mathrm{H}} 3.95\left(\mathrm{OCH}_{3}\right), 3.82\left(\mathrm{OCH}_{3}{ }^{\prime \prime}\right), 6 \mathbf{b}$ : $\left.3.95\left(\mathrm{OCH}_{3}\right), 3.81\left(\mathrm{OCH}_{3}{ }^{\prime \prime}\right)\right]$. Heteronuclear multiple bond correlation (HMBC) spectrum analysis confirmed their position, linked respectively to C-3 and C-3".

Compounds $\mathbf{6 a}$ and $\mathbf{6 b}$ were therefore determined to be stilbene dimers resulting from the linkage of two isorhapontin molecules, confirmed by the occurrence of 4 methoxyl groups ( 2 for each diastereoisomer) (Figure 3). Then, the only difference between the two diastereoisomers was their absolute stereochemistry on the two chiral carbons C-7" and C-8". trans position of H7" and H8" was determined analyzing the growth rates of Rotating-frame overhauser spectroscopy (ROESY) peaks, as a function of the mixing time from $100 \mathrm{~ms}$ to $400 \mathrm{~ms}$ acquired spectrum, leading to $6 \mathbf{a}\left(7^{\prime \prime} R^{*}, 8^{\prime \prime} R^{*}\right)$ and $\mathbf{6 b}$ $\left(7^{\prime \prime} S^{*}, 8^{\prime \prime} S^{*}\right)$ stereochemistry. To the best of our knowledge, this is the first time that diastereoisomeric isorhapontin dimers are reported from the plant in the literature. So far, identified piceasides reported in literature are mainly dimerization products of monomeric glycosylated stilbenes astringin and isorhapontin [23,24]. Different stilbene dimers had also been reported from other genera, such as Gnetum and Vitis [25-27]. In the continuation of Picea spp. isolated stilbene dimers denomination, compounds $6 \mathbf{a}$ and $\mathbf{6 b}$ will therefore be named piceasides $\mathrm{O}$ and $\mathrm{P}$ respectively.

Table 3. Nuclear Magnetic Resonance shifts of isolated molecule 6 from black spruce bark hot water extract ${ }^{1} \mathrm{H}$ and ${ }^{13} \mathrm{C}$ shifts and Heteronuclear Multiple Bond Correlation (HMBC) of $\mathbf{6} \mathbf{a}$ and $\mathbf{6 b}$ molecules.

\begin{tabular}{|c|c|c|c|c|c|}
\hline Position & $\delta_{H}(6 a)^{a}$ & $\delta_{C}(6 a)^{b}$ & $\delta_{H}(6 b)^{a}$ & $\delta_{C}(6 b)^{b}$ & HMBC (6a and 6b) \\
\hline 1 & & $139.7(d)$ & & $139.7(d)$ & \\
\hline 2 & $7.11(b r s)$ & $110.5(d)$ & $7.11(b r s)$ & $110.4(d)$ & $C-3,7,6,4$ \\
\hline 3 & & $144.3(s)$ & & $144.3(s)$ & \\
\hline 4 & & $148.0(d)$ & & $148.0(d)$ & \\
\hline 5 & & $131.5(d)$ & & $131.5(d)$ & \\
\hline 6 & $6.83(b r s)$ & $115.6(d)$ & $6.81(b r s)$ & $115.5(d)$ & \\
\hline 7 & $7.03(d, 16.3)$ & $128.6(d)$ & $7.03(d, 16.3)$ & $128.6(d)$ & C- $-8,1,2,6$ \\
\hline 8 & $6.87(d, 16)$ & $126.2(d)$ & $6.87(d, 16)$ & $126.2(d)$ & C- $7,9,1,10,14$ \\
\hline
\end{tabular}


Table 3. Cont.

\begin{tabular}{|c|c|c|c|c|c|}
\hline Position & $\delta_{H}(6 a)^{a}$ & $\delta_{C}(6 a)^{b}$ & $\delta_{H}(6 b)^{a}$ & $\delta_{C}(6 b)^{b}$ & HMBC (6a and 6b) \\
\hline 9 & & $131.9(d)$ & & $131.8(d)$ & \\
\hline 10 & 6.78 (overlap) & $105.7(d)$ & 6.78 (overlap) & $105.6(d)$ & $\mathrm{C}-11,8,9,12,14$ \\
\hline 11 & & $159.0(s)$ & & $159.0(s)$ & \\
\hline 12 & $6.45(t, 2.2)$ & $102.9(s)$ & $6.45(t, 2.2)$ & $102.9(s)$ & C- $10,14,13,11$ \\
\hline 13 & & $158.1(s)$ & & $158.1(s)$ & \\
\hline 14 & $6.62(t, 1.7)$ & $107.0(s)$ & $6.62(t, 1.7)$ & $107.0(s)$ & $C-13,12,8,10$ \\
\hline $1^{\prime}$ & 4.87 (overlap) & $100.4(s)$ & 4.87 (overlap) & $100.4(s)$ & C-11 \\
\hline $2^{\prime}$ & 3.37-3.51 (overlap) & $73.3(d)$ & $3.37-3.51$ (overlap) & $73.4(d)$ & \\
\hline $3^{\prime}$ & 3.37-3.51 (overlap) & $76.5(s)$ & 3.37-3.51 (overlap) & $76.5(s)$ & \\
\hline $4^{\prime}$ & 3.37-3.51 (overlap) & $70.0(d)$ & 3.37-3.51 (overlap) & $70.0(d)$ & \\
\hline $5^{\prime}$ & 3.37-3.51 (overlap) & $76.6(d)$ & 3.37-3.51 (overlap) & $76.6(d)$ & \\
\hline $6^{\prime}$ & $3.79(d d, 12.1,2.3)$ & $60.9(d)$ & $3.79(d d, 12.1,2.3)$ & $60.7(d)$ & $C-4^{\prime}, 5^{\prime}$ \\
\hline $1^{\prime \prime}$ & & $131.6(d)$ & & $131.6(d)$ & \\
\hline $2^{\prime \prime}$ & $6.93(d, 6.9)$ & $109.4(d)$ & $6.93(d, 6.9)$ & $109.3(d)$ & C-6", 4", 7", 3" $1^{\prime \prime}$ \\
\hline 3" & & $147.7(s)$ & & $147.7(s)$ & \\
\hline $4^{\prime \prime}$ & & $146.5(d)$ & & $146.5(d)$ & \\
\hline $5 "$ & 6.79 (overlap) & $114.8(s)$ & 6.79 (overlap) & $114.8(s)$ & $C-1 ", 3^{\prime \prime}$ \\
\hline $6 "$ & 6.80 (overlap) & $119.0(d)$ & 6.80 (overlap) & $118.8(d)$ & $C-7^{\prime \prime}, 1^{\prime \prime}$ \\
\hline $7^{\prime \prime}$ & $5.43(d, 8.8)$ & $94.0(d)$ & $5.44(d, 8.6)$ & $94.0(d)$ & C-8", $2^{\prime \prime}, 6^{\prime \prime}, 1^{\prime \prime}, 3^{\prime \prime}, 9^{\prime \prime}$ \\
\hline $8^{\prime \prime}$ & $4.51(d, 8.8)$ & $57.6(d)$ & $4.50(d, 8.6)$ & $57.6(d)$ & C-7", $9^{\prime \prime}, 5,10^{\prime \prime}, 14^{\prime \prime}$ \\
\hline $9^{\prime \prime}$ & & $143.8(d)$ & & $143.6(d)$ & \\
\hline $10^{\prime \prime}$ & $6.42(d d d, 3.8,2.2,1.5)$ & $107.6(d)$ & $6.42(d d d, 3.8,2.2,1.5)$ & $107.4(d)$ & C-11", $12^{\prime \prime}, 8^{\prime \prime}, 14^{\prime \prime}, 9^{\prime \prime}$ \\
\hline $11^{\prime \prime}$ & & $159.1(s)$ & & $159.1(s)$ & \\
\hline $12^{\prime \prime}$ & $6.50(t, 2.2)$ & $102.5(d)$ & $6.50(t, 2.2)$ & $102.3(d)$ & C-13", 11", 10", 14" \\
\hline $13 "$ & & $158.5(d)$ & & $158.5(d)$ & \\
\hline $14^{\prime \prime}$ & $6.34(d d, 2.2,1.4)$ & $109.0(d)$ & $6.31(d d, 2.2,1.4)$ & $108.9(d)$ & C-13", $12^{\prime \prime}, 10^{\prime \prime}, 8^{\prime \prime}$ \\
\hline $1^{\prime \prime \prime}$ & $4.79(d, 7,5)$ & $100.8(d)$ & $4.90(d, 7.6)$ & $100.9(d)$ & C-11" \\
\hline $2^{\prime \prime \prime}$ & 3.37-3.51 (overlap) & $73.5(s)$ & 3.37-3.51 (overlap) & $73.5(s)$ & \\
\hline $3^{\prime \prime \prime}$ & 3.37-3.51 (overlap) & $76.5(d)$ & 3.37-3.51 (overlap) & $76.5(d)$ & \\
\hline $4^{\prime \prime \prime}$ & 3.37-3.51 (overlap) & $69.7(d)$ & 3.37-3.51 (overlap) & $69.6(d)$ & \\
\hline $5^{\prime \prime \prime}$ & 3.37-3.51 (overlap) & $76.8(d)$ & 3.37-3.51 (overlap) & $76.8(d)$ & \\
\hline $6^{\prime \prime \prime}$ & $3.93(d d, 12.1,2.1)$ & $61.2(d)$ & $3.91(d d, 12.1,2.1)$ & $61.2(d)$ & $C-4^{\prime \prime}, 5^{\prime \prime}$ \\
\hline $\mathrm{OCH} 3$ & $3.95(s)$ & $55.4(s)$ & $3.95(s)$ & $55.4(s)$ & $C-3$ \\
\hline OCH3" & $3.82(s)$ & $55.0(d)$ & $3.81(s)$ & $55.0(d)$ & $C-3^{\prime \prime}$ \\
\hline
\end{tabular}

a: ${ }^{1} \mathrm{H}$ chemical shifts acquired at $500 \mathrm{MHz}$ in $\mathrm{CD}_{3} \mathrm{OD}$ with multiplicities and coupling constants expressed in $\mathrm{Hz}$ in parenthesis; ${ }^{\text {b: }}{ }^{13} \mathrm{C}$ chemicals shifts acquired at $125 \mathrm{MHz}$ in $\mathrm{CD}_{3} \mathrm{OD}$ with multiplicities in parenthesis. Identical chemical shifts for $\mathbf{6 a}$ and $\mathbf{6 b}$ might be interchangeable.

Stilbenes are represented in limited plant genera in nature and their distribution is very genus-specific [28]. Stilbenes are widely represented in Picea spp. This is particularly the case with the glucosides trans-astringin, trans-isorhapontin and trans-piceid which had been reported in several studies on chemical composition of bark extracts of Picea species [5,29]. While trans-resveratrol was identified in several very different plants, from cocoa to grapes and also Asian herbal medicine Polygonum cuspidatum, trans-isorhapontin which is almost ubiquitous in Picea spp. was reported in only two species outside of Picea genus: the flowering plants Veratrum taliense and Rheum undulatum [28]. The absence of trans-isorhapontin in dietary source of stilbenoids such as wine, berries and vegetables led to very poor investigation on its potential biological activity. Indeed, except an in vitro antileukemic activity reported by Mannila and Talvitie [29], no other pharmacological study was conducted on trans-isorhapontin. However, with the recent identification of trans-isorhapontin's aglycon, trans-isorhapontingenin, in a traditional Chinese herbal medicine Gnetum cleistostachyum with anti-cancer effects [30], several studies had since been performed on the potential anti-cancer activity of this molecule [31]. There are also studies on its activities such as cardioprotective [32] and antioxidant [33]. We report here the Picea mariana bark extract as a rich source of these two compounds, the trans-isorhapontin reaching the concentration of $11971 \mathrm{mg} / 100 \mathrm{~g}$ of dry extract $(12.0 \%$ of the total extract) and its aglycon $3654 \mathrm{mg} / 100 \mathrm{~g}$ dry extract (3.7\%) (Table 2). The abundance of these methoxylated stilbenes in the extract confirm the methoxylation pattern of Picea mariana bark polyphenols revealed previously by our group for its proanthocyanidins [34].

Pharmacological interests had risen for piceatannol since it was demonstrated to exhibit anticancer properties [35], supposedly superior to trans-resveratrol [36]. Very few studies considered its glucoside derivative, trans-astringin, for which a similar chemopreventive activity was demonstrated [35]. 
We found high contents of trans-astringin in black spruce bark extract, the maximum being $4613 \mathrm{mg} / 100 \mathrm{~g}$ of dry extract (4.6\%) (Table 2). As for the most well-known stilbene, trans-resveratrol, multiple researches reported anticancer, anti-inflammatory, anti-hyperlipidemic and cardioprotective activities. Previously identified and quantified in ethyl acetate fraction of P. mariana bark extract [1], we are reporting here a high content of trans-resveratrol in the crude water extract from the optimized extraction at $302 \mathrm{mg} / 100 \mathrm{~g}$ of dry extract representing $0.3 \%$ of the dry bark. In addition, we determined in this study for the first time, the presence of trans-piceid in high concentration in Picea mariana bark extract reaching a maximum of $3094 \mathrm{mg} / 100 \mathrm{~g}$ of dry extract. Less studied than its aglycon resveratrol, trans-piceid is nonetheless very interesting from a pharmacological point of view as therapeutic properties were reported, namely anticancer, cardioprotective, anti-inflammatory [37] and even for the treatment of Parkinson disease [38].

\section{Materials and Methods}

\subsection{Plant Material}

Bark of black spruce was supplied by Boisaco Inc. sawmill (Quebec, QC, Canada) from debarking of logs. A voucher specimen was deposited at the Herbarium Louis-Marie of the Universite Laval, Québec, Canada, with reference number QFA 0358054. In the laboratory, the raw material was separated from wood residues and lichens, washed and then air-dried at ambient temperature for 5 days. Bark was milled and sieved to select particles between 0.5 and $0.25 \mathrm{~mm}$.

\subsection{Factorial Design for Multiple Extraction Experiment}

A $3 \times 3 \times 2$ factorial experimental design was set up in order to evaluate the relationship between the response factors measured and the extraction variables. The objective was to select the best conditions for extraction optimization. The three independent variables considered were extraction time $(60,90,120 \mathrm{~min})$, ratio bark/water $(200 \mathrm{mg} / \mathrm{mL}, 100 \mathrm{mg} / \mathrm{mL}, 50 \mathrm{mg} / \mathrm{mL})$ and temperature $\left(80{ }^{\circ} \mathrm{C}\right.$, $100{ }^{\circ} \mathrm{C}$ ); response factors measured were extraction yield, amount of phytochemicals (total phenol content, total proanthocyanidin content, total sugar content) and antioxidant activity.

\subsection{Extraction Procedure for Optimization Experiment}

Air-dried bark (5, 10 and $20 \mathrm{~g}$ according to selected ratio) was extracted with $100 \mathrm{~mL}$ of hot distilled water under reflux and filtered with a Whatman No. 3 filter [39], then $100 \mathrm{~mL}$ of water was used to wash the extracted bark. Aqueous filtrate was freeze-dried with a Labconco FreeZone $12 \mathrm{~L}$ Console Freeze Drying System (Labconco, Kansas City, MO, USA). Each extraction was performed in duplicate.

\subsection{Isolation and Characterization of the Hot Water Extract Constituents}

Air dried black spruce bark, $150 \mathrm{~g}$ (corresponding to $134 \mathrm{~g}$ of oven dried bark), was extracted with $3 \mathrm{~L}$ of distilled hot water under reflux for $1 \mathrm{~h}$. After filtration with a Whatman No. 3 filter paper, the extract was freeze-dried with a Labconco FreeZone 12 L Console Freeze Drying System (Labconco, Kansas City, MO USA) to yield $14.9 \mathrm{~g}$ of dry extract. Black spruce hot water extract powder (11.23 g) was fractionated on a silica column (63-200 $\mu \mathrm{m}$ particle size) using a mixture of methylene chloride/methanol solvents from 10 to $100 \%$ methanol. Eight fractions were obtained, from which some compounds were purified in semi-preparative HPLC: Si-1 $(102.1 \mathrm{mg})$ yielded compound 8 (6.1 mg), Si-2 (707.9 mg) for compound 7 (15.3 mg), Si-4 (1222.2 mg) for compounds 4 (27.8 mg) and 5 (67.4 mg), Si-5 (1687.9) for compound 3 (86.4 mg). Fraction Si-6 (1771.7 mg) was further purified on a sephadex column, resulting in 15 sub-fractions. Compounds $1(9.8 \mathrm{mg})$ and $\mathbf{2}(13.9 \mathrm{mg})$ were then isolated from fractions Si-6.1 $(99.3 \mathrm{mg})$ and $6.2(45.5 \mathrm{mg})$, and compound $6(15.4 \mathrm{mg})$ from Si-6.8 $(106.6 \mathrm{mg})$. Isolation of pure compounds was performed by HPLC on a semi-preparative Zorbax SB-C18 column $(21.2 \times 250 \mathrm{~mm}, 7 \mu \mathrm{m})$ (Agilent Technologies, Santa Clara, CA, USA) with an Agilent 
Technologies 1260 Infinity instrument. The flow rate was $10 \mathrm{~mL} / \mathrm{min}$ of several elution gradients of water/methanol adapted to targeted molecules' polarity. The absorbance was read at 280, 320 and $340 \mathrm{~nm}$ with a photodiode array detector. Identification of 8 purified compounds was achieved by compiling information from UV wavelength, mass spectra and NMR shifts.

\subsection{Phytochemicals Assessments of the Extracts}

\subsubsection{Total Phenol Content}

Total phenol content was measured for the 36 extracts with the Folin Ciocalteu test according to the method reported by St-Pierre et al. [40]. Extract samples of $500 \mu \mathrm{L}$ were diluted to a concentration of $100 \mu \mathrm{g} / \mathrm{mL}$ and reacted with $2.5 \mathrm{~mL}$ Folin Ciocalteu reagent $(1: 10 \mathrm{v} / \mathrm{v})$ and $2.0 \mathrm{~mL}$ sodium carbonate aqueous solution $(75 \mathrm{~g} / \mathrm{L})$ during $10 \mathrm{~min}$ in a $50{ }^{\circ} \mathrm{C}$ hot bath. The absorbance measured at $760 \mathrm{~nm}$ using a UV-visible spectrophotometer Varian Cary50 (Varian Inc., Walnut Creek, CA, USA) was used to express the phenol content in terms of gallic acid equivalent (mg GAE/g of dry extract) with a calibration curve obtained for gallic acid $\left(y=0.0227 x-0.0083 ; R^{2}=0.9994\right)$.

\subsubsection{Proanthocyanidin Content}

Proanthocyanidin content of the 36 extracts was determined by the method described by Porter et al. [41]. Each extract $(1 \mathrm{~mL}$, concentration of $480 \mu \mathrm{g} / \mathrm{mL})$ was mixed with $200 \mu \mathrm{L}$ of $2 \%$ ferrous ammonium sulfate $\left(\mathrm{FeNH}_{4}\left(\mathrm{SO}_{4}\right)_{2}\right)$ in $\mathrm{HCl}$ solution $(2 \mathrm{~N})$, and $6 \mathrm{~mL}$ of n-butanol: $\mathrm{HCl}(95: 5)$ and reacted for $50 \mathrm{~min}$ in a $95{ }^{\circ} \mathrm{C}$ hot bath. Proanthocyanidin content was determined by reading absorbance on a UV-Vis spectrophotometry at $550 \mathrm{~nm}$ and expressed with a cyanidin chloride calibration curve $\left(y=0.0298 x ; R^{2}=0.9953\right)$, in cyanidin chloride equivalent CyE/g dry extract.

\subsubsection{Total Sugar Content}

Total sugar content of 36 extracts was determined by the phenol-sulfuric acid method adapted from Albalasmeh et al. [42]. Briefly, $1 \mathrm{~mL}$ of extract $(90 \mu \mathrm{g} / \mathrm{mL})$ was mixed with $500 \mu \mathrm{L}$ of phenol reagent $(4 \% \mathrm{~m} / v$ water) and $2.5 \mathrm{~mL}$ of concentrated sulfuric acid $(36 \mathrm{~N})$ and reacted for $10 \mathrm{~min}$ in darkness. Absorbance was read at $490 \mathrm{~nm}$ and sugar content was expressed with an Arabinose-Rhamnose-Galactose-Fructose calibration curve (mg ARGF/g dry extract) $\left(y=0.0097 x+0.022 ; R^{2}=0.9960\right)$.

\subsubsection{DPPH Assay}

The antioxidant activity of the 36 extracts was evaluated with the radical DPPH (2,2-diphenyl-1-picrylhydrazyl) using a method adapted from Li et al. [43]. In a 96-well plate, $100 \mu \mathrm{L}$ of each diluted extract in methanol $(100 \mu \mathrm{g} / \mathrm{mL})$ reacted with $150 \mu \mathrm{L} \mathrm{DPPH}(137 \mu \mathrm{M})$. The reduction of the radical resulted in a color change that was recorded after $30 \mathrm{~min}$ on a spectrophotometer at $515 \mathrm{~nm}$ wavelength. Percentage of DPPH radical inhibition was calculated against a blank and expressed in Trolox Equivalent ( $\mu \mathrm{mol} \mathrm{TE} / \mathrm{g}$ dry extract) according to the standard curve $(y=0.0782 x+0.0142$; $\left.R^{2}=0.9785\right)$.

\subsection{HPLC-DAD Analysis}

In order to evaluate the influence of the extraction parameters on the monomeric phenolic profile of the extract, the 36 black spruce bark extracts were tested using High Performance Liquid Chromatography-Diode Array Detector analysis. The separation was performed on an Agilent Technologies Series 1100 Instrument equipped with a reverse phase Zorbax SB-C18 column $(4.6 \times 250 \mathrm{~mm}, 5 \mu \mathrm{m})$ (Agilent Technologies, Santa Clara, CA, USA). The system was run with the following elution program, with solvents (A) 1\% $(v / v)$ formic acid in water and (B) acetonitrile: $5-15 \%$ $B$ in $10 \mathrm{~min}$, isocratic $15 \%$ B for $5 \mathrm{~min}, 15-30 \%$ B in $20 \mathrm{~min}$, isocratic $30 \%$ B for $5 \mathrm{~min}, 30-40 \%$ B in $5 \mathrm{~min}$, isocratic $40 \%$ B for $5 \mathrm{~min}$. Then, $10 \mathrm{~min}$ post run at initial conditions was set for column equilibration. 
The flow rate was $0.7 \mathrm{~mL} / \mathrm{min}$ and the column temperature, $30^{\circ} \mathrm{C}$. Black spruce extracts were injected at a concentration of $1 \mathrm{mg} / \mathrm{mL}, 10 \mu \mathrm{L}$ injection volume. UV detection was set at 280, 320 and $340 \mathrm{~nm}$.

\subsection{Chemometric Analysis}

In order to highlight the variability observed between the 36 studied extracts by HPLC-DAD analyses, the peak areas of main phenolic compounds were then submitted to an exploratory chemometric analysis. To achieve it, a principal component analysis was applied on the dataset made of 36 samples $\times 8$ variables (major extract constituents) [20]. The analysis was performed with SAS software package 9.4 (SAS Institute Inc., Cary, NC, USA).

\subsection{HRMS and NMR Analysis}

High Resolution-Mass Spectrometry analyses were performed on a 6210 Time-of-Flight (Agilent Technologies, Santa Clara, CA, USA) with electrospray in positive mode (ESI+), coupled with HPLC. The ESI-TOF specifications were as follow: drying gas, $5 \mathrm{~L} / \mathrm{min}$; gas temperature, $325{ }^{\circ} \mathrm{C}$; nebulizer pressure, 30 psig; skimmer, $65 \mathrm{~V}$; capillary voltage, $4000 \mathrm{~V}$ and fragmentor, $175 \mathrm{~V}$. Recorded from 100 to $1000 \mathrm{~m} / z$, mass spectra were then analyzed on an Agilent MassHunter Qualitative Analysis software (version B.02.00, Agilent Technologies, Santa Clara, CA, USA) Nuclear magnetic resonance was performed on an Agilent 400-MR DD2 system (Agilent Technologies, Santa Clara, CA, USA), either for one-dimensional ${ }^{1} \mathrm{H}$ and ${ }^{13} \mathrm{C}$ NMR or two-dimensional NMR (HSQC, HMBC, COSY, NOESY and ROESY) spectroscopy. NMR shifts of isolated compounds were in accordance with literature: $\mathbf{1}$ and $\mathbf{2}$ [44]; 3, 4, 5 and 8 [45], 7 [46] (Supplementary Material).

Compound 6 was isolated as a dark yellow amorphous solid $(15.4 \mathrm{mg}) ;[\alpha]_{\mathrm{D}}^{22}-52.0^{\circ}(\mathrm{c}=0.25$, $\mathrm{CH}_{3} \mathrm{OH}$ ); $\mathrm{UV}\left(\mathrm{CH}_{3} \mathrm{OH}\right) \lambda_{\max }(\log \varepsilon): 285$ (4.5), 310 (4.7), 330 (4.7) nm; Infrared IR (Attenuated total reflection ATR): 3349, 2950, 2837, 1452, 1414, 1125, 1026, 984, $667 \mathrm{~cm}^{-1} ;{ }^{1} \mathrm{H}$ NMR (CD $\left.{ }_{3} \mathrm{OD}, 500 \mathrm{MHz}\right)$, ${ }^{13} \mathrm{C}$ NMR $\left(\mathrm{CD}_{3} \mathrm{OD}, 126 \mathrm{MHz}\right)$, HMBC: see Table 3; Positive ESI-TOF-HRMS, $m / z: 856.3026\left[\mathrm{M}+\mathrm{NH}_{4}\right]^{+}$, calculated exact mass 838.2684 for $\mathrm{C}_{42} \mathrm{H}_{46} \mathrm{O}_{18}$.

\subsection{Statistical Analysis}

Yield, polyphenol, proanthocyanidin, sugar and antioxidant capacity assessments were expressed as means of triplicates \pm standard deviation. Data sets were submitted to factorial analysis of variance (ANOVA), and contrast analysis (planned comparisons) using SAS software 9.4 (SAS Institute Inc., Cary, NC, USA).

\section{Conclusions}

We have demonstrated in this research that the chemical composition of hot water extracts of black spruce bark was affected by extraction parameters. Proportion of different families of molecules can be preferentially targeted using different extraction parameters. Thus, the recovery of phenolic compounds is favored over sugars when a low ratio (bark/water) is applied. However, high temperatures are not favorable towards extracting the phenolic compounds of interest, even though these are advantageous to getting high yields. Hence, for an overall optimized extraction of polyphenols from black spruce bark, the most suitable parameters are $80{ }^{\circ} \mathrm{C}$ and ratio $50 \mathrm{mg} / \mathrm{mL}$. Moreover, chemometric analysis demonstrated that specific phenolic compounds classes (hydroxycinnamic acids and stilbenes) can be targeted by selected extraction parameters. Even if none of the extraction parameters allowed for classes discrimination, the $80{ }^{\circ} \mathrm{C}$ temperature was confirmed to be the best temperature parameter for extraction of polyphenols. The chemometrics therefore represents an efficient tool to examine the influence of extraction parameters.

In addition, the great amounts of bioactive resveratrol and stilbenes' glycosides, such as astringin and isorhapontin, which make about a quarter of the whole hot water bark extract composition, may indicate a potential application of this extract as natural health product. The presence of piceid, the resveratrol glycoside, is herein reported for the first time in Picea mariana. In addition, the 
identification of novel diastereoisomeric piceasides, a first example of isorhapontin dimerization in nature, demonstrated that work needs to be pursued on further chemical characterization of black spruce bark extract. The repeatability of the chemical composition of the studied 36 crude hot water extracts from Picea mariana bark, combined with its previously determined safety, makes this extract applicable as a natural health product in food additives, functional foods, cosmetic ingredients and pharmaceuticals.

Supplementary Materials: Supplementary Materials are available online. Statistics: Figure S1. Variance explained for the principal component analysis; Table S1. ANOVA and contrasts statistical experiments, general linear model (GLM) procedure on SAS software. $\operatorname{Pr}>\mathrm{F}$, the level of significance, has to reach 0.05 (for $\alpha=5 \%$ ) for the model to be statistically significant. Contrasts are calculated if ANOVA is significant; Table S2. Pearson correlation coefficients and $p$ values from statistical significance testing (in italics); NMR: ${ }^{1} \mathrm{H}$ and ${ }^{13} \mathrm{C}$ NMR shifts of isolated molecules 1-5 and 7-8 from black spruce bark hot water extract; Figure S2. ${ }^{1} \mathrm{H}$ NMR of compound 6; Figure S3. ${ }^{13} \mathrm{C}$ NMR of compound 6; Figure S4. HSQC NMR of compound 6; Figure S5. HMBC NMR of compound 6.

Acknowledgments: The authors are grateful for the financial support of the Natural Sciences and Engineering Research Council of Canada NSERC (Research Grant to T. Stevanovic RDC-CRSNG project RDCPJ448497-13), Boisaco Inc and Nuvac EcoScience, and of the Faculty of Forestry, Geography, and Geomatics of the Université Laval (Canada). The thanks are also extended to M. Yves Bédard for technical support and M. Pierre Audet for nuclear magnetic resonance and mass spectra expertise.

Author Contributions: N.F., N.R.M. and T.S. conceived and designed the experiments; N.F. and N.R.M. performed the experiments; N.F. and N.R.M. analyzed the data; N.F. prepared the manuscript; N.R.M. and T.S. reviewed the paper. All authors have approved the final manuscript.

Conflicts of Interest: The authors declare no conflict of interest.

\section{References}

1. Garcia-Perez, M.E.; Royer, M.; Herbette, G.; Desjardins, Y.; Pouliot, R.; Stevanovic, T. Picea mariana bark: A new source of trans-resveratrol and other bioactive polyphenols. Food Chem. 2012, 135, 1173-1182. [CrossRef] [PubMed]

2. Francezon, N.; Stevanovic, T. Integrated process for the production of natural extracts from black spruce bark. Ind. Crops Prod. 2017, 108, 348-354. [CrossRef]

3. Counet, C.; Callemien, D.; Collin, S. Chocolate and cocoa: New sources of trans-resveratrol and trans-piceid. Food Chem. 2006, 98, 649-657. [CrossRef]

4. Wang, Y.; Catana, F.; Yang, Y.; Roderick, R.; Van Breemen, R.B. An LC-MS method for analyzing total resveratrol in grape juice, cranberry juice, and in wine. J. Agric. Food Chem. 2002, 50, 431-435. [CrossRef] [PubMed]

5. Manners, G.D.; Swan, E.P. Stilbenes in the barks of five canadian Picea species. Phytochemistry 1971, 10, 607-610. [CrossRef]

6. Roupe, K.A.; Remsberg, C.M.; Yáñez, J.A.; Davies, N.M. Pharmacometrics of stilbenes: Seguing towards the clinic. Curr. Clin. Pharmacol. 2006, 1, 81-101. [CrossRef] [PubMed]

7. Frémont, L. Biological effects of resveratrol. Life Sci. 2000, 66, 663-673. [CrossRef]

8. Clinical trial, C. A Single Dose Study of Epn-07 by Oral Gavage in Rats with a 14 Day Recovery Period (up and down Procedure), Confidential; Charles River Laboratories: Edinburgh, UK, 2012.

9. Chemat, F.; Vian, M.A.; Cravotto, G. Green extraction of natural products: Concept and principles. Int. J. Mol. Sci. 2012, 13, 8615-8627. [CrossRef] [PubMed]

10. Hartonen, K.; Riekkola, M.-L. Chapter 2-Water as the first choice green solvent. In The Application of Green Solvents in Separation Processes; Pena-Pereira, F., Tobiszewski, M., Eds.; Elsevier: Amsterdam, The Netherlands, 2017; pp. 19-55. ISBN 9780128052976.

11. Geoffroy, T.R.; Fortin, Y.; Stevanovic, T. Hot-water extraction optimization of sugar maple (Acer saccharum Marsh.) and red maple (Acer rubrum L.) bark applying principal component analysis. J. Wood Chem. Technol. 2017, 1-12. [CrossRef]

12. Royer, M.; Prado, M.; García-Pérez, M.E.; Diouf, P.N.; Stevanovic, T. Study of nutraceutical, nutricosmetics and cosmeceutical potentials of polyphenolic bark extracts from canadian forest species. PharmaNutrition 2013, 1, 158-167. [CrossRef] 
13. Stevanovic, T.; Diouf, P.N.; Garcia-Perez, M.E. Bioactive polyphenols from healthy diets and forest biomass. Curr. Nutr. Food Sci. 2009, 5, 264-295. [CrossRef]

14. Garcia-Perez, M.E.; Royer, M.; Duque-Fernandez, A.; Diouf, P.N.; Stevanovic, T.; Pouliot, R. Antioxidant, toxicological and antiproliferative properties of canadian polyphenolic extracts on normal and psoriatic keratinocytes. J. Ethnopharmacol. 2010, 132, 251-258. [CrossRef] [PubMed]

15. Schneider, M.J.; Montali, J.A.; Zen, D.; Stanton, C.E. Alkaloids of Picea. J. Nat. Prod. 1991, 54, 905-909. [CrossRef]

16. Kemppainen, K.; Siika-Aho, M.; Pattathil, S.; Giovando, S.; Kruus, K. Spruce bark as an industrial source of condensed tannins and non-cellulosic sugars. Ind. Crops Prod. 2014, 52, 158-168. [CrossRef]

17. Giannoccaro, E.; Wang, Y.J.; Chen, P. Effects of solvent, temperature, time, solvent-to-sample ratio, sample size, and defatting on the extraction of soluble sugars in soybean. J. Food Sci. 2006, 71. [CrossRef]

18. Elleuch, M.; Bedigian, D.; Roiseux, O.; Besbes, S.; Blecker, C.; Attia, H. Dietary fibre and fibre-rich by-products of food processing: Characterisation, technological functionality and commercial applications: A review. Food Chem. 2011, 124, 411-421. [CrossRef]

19. Xu, X.; Jiang, J.; Liang, Y.; Yi, L.; Cheng, J. Chemical fingerprint analysis for quality control of Fructus Aurantii Immaturus based on HPLC-DAD combined with chemometric methods. Anal. Methods 2010, 2, 2002-2010. [CrossRef]

20. Meda, N.; Rott, M.; Suwal, S.; Poubelle, P.; Stevanovic, T. Chemometrics-based approach to analysis of phenolic fingerprints of red and sugar maple bud extracts. Austin Biochem. 2017, 2, 1009.

21. Pan, H.; Lundgren, L.N. Phenolic extractives from root bark of Picea abies. Phytochemistry 1995, 39, 1423-1428. [CrossRef]

22. Carnachan, S.M.; Harris, P.J. Ferulic acid is bound to the primary cell walls of all gymnosperm families. Biochem. Syst. Ecol. 2000, 28, 865-879. [CrossRef]

23. Li, S.H.; Niu, X.M.; Zahn, S.; Gershenzon, J.; Weston, J.; Schneider, B. Diastereomeric stilbene glucoside dimers from the bark of norway spruce (Picea abies). Phytochemistry 2008, 69, 772-782. [CrossRef] [PubMed]

24. Gabaston, J.; Richard, T.; Biais, B.; Waffo-Teguo, P.; Pedrot, E.; Jourdes, M.; Corio-Costet, M.-F.; Mérillon, J.-M. Stilbenes from common spruce (Picea abies) bark as natural antifungal agent against downy mildew (Plasmopara viticola). Ind. Crops Prod. 2017, 103, 267-273. [CrossRef]

25. Waffo-Teguo, P.; Lee, D.; Cuendet, M.; Mérillon, J.-M.; Pezzuto, J.M.; Kinghorn, A.D. Two new stilbene dimer glucosides from grape (Vitis vinifera) cell cultures. J. Nat. Prod. 2001, 64, 136-138. [CrossRef] [PubMed]

26. Huang, K.-S.; Wang, Y.-H.; Li, R.-L.; Lin, M. Five new stilbene dimers from the lianas of Gnetum hainanense. J. Nat. Prod. 2000, 63, 86-89. [CrossRef] [PubMed]

27. Yao, C.-S.; Lin, M. Bioactive stilbene dimers from Gnetum cleistostachyum. Nat. Prod. Res. 2005, 19, 443-448. [CrossRef] [PubMed]

28. Rivière, C.; Pawlus, A.D.; Mérillon, J.-M. Natural stilbenoids: Distribution in the plant kingdom and chemotaxonomic interest in Vitaceae. Nat. Prod. Rep. 2012, 29, 1317-1333. [CrossRef] [PubMed]

29. Mannila, E.; Talvitie, A. Stilbenes from Picea abies bark. Phytochemistry 1992, 31, 3288-3289. [CrossRef]

30. Yao, C.-S.; Lin, M.; Liu, X.; Wang, Y. Stilbenes from Gnetum cleistostachyum. Acta Chim. Sin. 2003, 61, 1331-1334.

31. Liang, Y.; Zhu, J.; Huang, H.; Xiang, D.; Li, Y.; Zhang, D.; Li, J.; Wang, Y.; Jin, H.; Jiang, G. SESN2/sestrin 2 induction-mediated autophagy and inhibitory effect of isorhapontigenin (ISO) on human bladder cancers. Autophagy 2016, 12, 1229-1239. [CrossRef] [PubMed]

32. Li, H.-L.; Wang, A.-B.; Huang, Y.; Liu, D.-P.; Wei, C.; Williams, G.M.; Zhang, C.-N.; Liu, G.; Liu, Y.-Q.; Hao, D.-L. Isorhapontigenin, a new resveratrol analog, attenuates cardiac hypertrophy via blocking signaling transduction pathways. Free Radic. Biol. Med. 2005, 38, 243-257. [CrossRef] [PubMed]

33. Fang, Y.N.; Liu, G.T. Effect of isorhapontigenin on respiratory burst of rat neutrophils. Phytomedicine 2002, 9, 734-738. [CrossRef] [PubMed]

34. Diouf, P.N.; Tibirna, C.M.; García-Pérez, M.-E.; Royer, M.; Dubé, P.; Stevanovic, T. Structural elucidation of condensed tannin from Picea mariana bark. J. Biomater. Nanobiotechnol. 2013, 4, 1-8. [CrossRef]

35. Waffo-Téguo, P.; Hawthorne, M.E.; Cuendet, M.; Mérillon, J.-M.; Kinghorn, A.D.; Pezzuto, J.M.; Mehta, R.G. Potential cancer-chemopreventive activities of wine stilbenoids and flavans extracted from grape (Vitis vinifera) cell cultures. Nutr. Cancer 2001, 40, 173-179. [CrossRef] [PubMed] 
36. Piotrowska, H.; Kucinska, M.; Murias, M. Biological activity of piceatannol: Leaving the shadow of resveratrol. Mutat. Res. Rev. Mutat. Res. 2012, 750, 60-82. [CrossRef] [PubMed]

37. Du, Q.-H.; Peng, C.; Zhang, H. Polydatin: A review of pharmacology and pharmacokinetics. Pharm. Biol. 2013, 51, 1347-1354. [CrossRef] [PubMed]

38. Chen, Y.; Zhang, D.-Q.; Liao, Z.; Wang, B.; Gong, S.; Wang, C.; Zhang, M.-Z.; Wang, G.-H.; Cai, H.; Liao, F.-F. Anti-oxidant polydatin (piceid) protects against substantia nigral motor degeneration in multiple rodent models of Parkinson's disease. Mol. Neurodegener. 2015, 10, 4. [CrossRef] [PubMed]

39. Diouf, P.N.; Stevanovic, T.; Cloutier, A. Study on chemical composition, antioxidant and anti-inflammatory activities of hot water extract from picea mariana bark and its proanthocyanidin-rich fractions. Food Chem. 2009, 113, 897-902. [CrossRef]

40. St-Pierre, F.; Achim, A.; Stevanovic, T. Composition of ethanolic extracts of wood and bark from Acer saccharum and Betula alleghaniensis trees of different vigor classes. Ind. Crops Prod. 2013, 41, 179-187. [CrossRef]

41. Porter, L.J.; Hrstich, L.N.; Chan, B.G. The conversion of procyanidins and prodelphinidins to cyanidin and delphinidin. Phytochemistry 1985, 25, 223-230. [CrossRef]

42. Albalasmeh, A.A.; Berhe, A.A.; Ghezzehei, T.A. A new method for rapid determination of carbohydrate and total carbon concentrations using UV spectrophotometry. Carbohydr. Polym. 2013, 97, 253-261. [CrossRef] [PubMed]

43. Li, L.; Henry, G.E.; Seeram, N.P. Identification and bioactivities of resveratrol oligomers and flavonoids from Carex folliculata seeds. J. Agric. Food Chem. 2009, 57, 7282-7287. [CrossRef] [PubMed]

44. Struijs, K.; Vincken, J.-P.; Verhoef, R.; van Oostveen-van Casteren, W.H.; Voragen, A.G.; Gruppen, H. The flavonoid herbacetin diglucoside as a constituent of the lignan macromolecule from flaxseed hulls. Phytochemistry 2007, 68, 1227-1235. [CrossRef] [PubMed]

45. Mulat, D.G.; Latva-Mäenpää, H.; Koskela, H.; Saranpää, P.; Wähälä, K. Rapid chemical characterisation of stilbenes in the root bark of Norway spruce by off-line HPLC/DAD-NMR. Phytochem. Anal. 2014, 25, 529-536. [CrossRef] [PubMed]

46. Commodari, F.; Khiat, A.; Ibrahimi, S.; Brizius, A.R.; Kalkstein, N. Comparison of the phytoestrogen trans-resveratrol $\left(3,4^{\prime}, 5\right.$-trihydroxystilbene) structures from X-ray diffraction and solution NMR. Magn. Reson. Chem. 2005, 43, 567-572. [CrossRef] [PubMed]

Sample Availability: Samples of the compounds 1-8 are available from the authors.

(C) 2017 by the authors. Licensee MDPI, Basel, Switzerland. This article is an open access article distributed under the terms and conditions of the Creative Commons Attribution (CC BY) license (http:// creativecommons.org/licenses/by/4.0/). 